\title{
As apropriações do Facebook pelas bibliotecas públicas estaduais brasileiras
}

\author{
Alberto Calil Junior \\ Doutor; Instituição Universidade Federal do Estado do Rio de Janeiro; \\ caliljr@unirio.br \\ Gabriela Almendra \\ Bacharela; Universidade Federal do Estado do Rio de Janeiro; \\ gabrielaalmendra@gmail.com
}

Resumo: Este artigo apresenta um estudo realizado sobre as apropriações do Facebook por quatro Bibliotecas Públicas Estaduais Brasileiras: Biblioteca Pública do Estado do Acre, Biblioteca Pública do Paraná, Biblioteca Pública do Estado de Pernambuco e Biblioteca de São Paulo. O estudo aborda, com base em revisão de literatura, os conceitos de Biblioteca Pública, mediação sociotécnica e mídia social, e questiona o papel da Biblioteca Pública na sociedade contemporânea. A pesquisa ainda afirma que as bibliotecas, através da mediação, devem reconhecer a importância de seu espaço como local de diálogo. Para tanto, foram analisadas as mensagens postadas nas fan pages das Bibliotecas escolhidas durante o período de janeiro a junho de 2013. Conclui-se que a mídia social aqui estudada ainda não é utilizada em todo seu potencial.

Palavras-chave: Bibliotecas públicas estaduais. Mediação da informação. Competência informacional. Mídias sociais. Facebook.

\section{Introdução}

Periodicamente, o Comitê Gestor da Internet publica um conjunto de dados relativos ao uso das tecnologias da informação e comunicação (TICs) no país. No relatório do ano de 2012 (COMITÊ GESTOR..., 2012), assinala-se que as ferramentas de redes sociais na Internet vêm se configurando como uma das principais portas de entrada na Internet para muitos brasileiros. Já em relação ao acesso, o relatório relativo ao ano de 2013 (COMITÊ GESTOR..., 2014) aponta que 43\% dos domicílios brasileiros possuíam acesso à Internet, enquanto que, de acordo com os dados do Instituto Brasileiro de Opinião Pública e Estatística (IBOPE) de 2013, o Brasil possui 105,1 milhões de internautas. 
A penetração das TICs no cotidiano de milhões de brasileiros incita a reflexão sobre os seus usos, não apenas pelos seus usuários, mas também por instituições, como, por exemplo, as Bibliotecas Públicas (BP). Tais instituições possuem, idealmente, a sua relevância na sociedade contemporânea, uma vez que seu conceito se baseia no fornecimento igualitário de acesso a todos os cidadãos, além da disponibilização de todo o tipo de conhecimento à comunidade (FUNDAÇÃO BIBLIOTECA NACIONAL, 2010). De acordo com Suaiden (2000), as BPs são o grande centro disseminador da informação, pois prestam serviços para todos os segmentos da sociedade sem levar em consideração a condição social, educacional e cultural de seus usuários.

$\mathrm{Na}$ esteira do debate sobre a presença das BPs na sociedade brasileira, o presente artigo apresenta o mapeamento dos usos do Facebook, bem como discute algumas das apropriações da referida mídia social realizadas por quatro Bibliotecas Públicas Estaduais (BPEs) brasileiras, a saber: Biblioteca Púbica do Estado do Acre, Biblioteca Pública do Paraná, Biblioteca Pública do Estado de Pernambuco e Biblioteca de São Paulo. Optou-se por analisar uma biblioteca de cada região brasileira ${ }^{1}$, chegando-se ao número de 4 bibliotecas, pois, na época da investigação, nenhuma das BPEs da região centro-oeste fazia uso da mídia social aqui em análise. Soma-se à importância de estudarmos as BPs, sua história e relação com a sociedade brasileira, além da necessidade de sabermos como tal mídia social é utilizada como ferramenta de mediação entre usuários e bibliotecas.

Ademais, no estudo das mídias sociais, é relevante a abordagem a partir de uma dupla perspectiva. De um lado, faz-se necessário o estudo do contexto de surgimento da noçãode mídias sociais em diálogo com outras categorias - web 2.0, biblioteca 2.0 -, considerando a partilha de um conjunto de características - colaboração, interação, dinamismo e compartilhamento - que, para alguns autores, promovem uma modificação de paradigmas (MANESS, 2007).

Por outro lado, faz-se necessário o debate em torno da noção de mediação da informação, visto que o Facebook é considerado um ambiente que pode promover diálogo entre o bibliotecário e o usuário, possibilitando que a comunicação e a interação ocorram fora das paredes físicas de uma unidade informacional. O ciberespaço demanda um conjunto de habilidades técnicas, cognitivas e sociais para 
que o usuário consiga suprir sua necessidade informacional. Esse conjunto de habilidades é explorado no uso da competência informacional em ambiente digital.

\section{0 conceito de biblioteca pública e o seu reflexo na sociedade}

A discussão conceitual da terminologia $\mathrm{BP}$ não é nova. O Dicionário de Biblioteconomia e Arquivologia, de Cunha e Cavalcanti (2008), apresenta uma compilação de verbetes que, segundo os autores, possui uso potencial no cotidiano de bibliotecários, arquivistas e profissionais da ciência da informação (2008). Nesse documento, é veiculada uma definição de BP que os autores Jesse H. Shera e Margaret E. Egan editaram na obra Bibliographic Organization, de 1951. Para eles, a BP é aquela "[...] que é posta à disposição da coletividade de uma região, município ou estado, e que é financiada principalmente por dotações governamentais." (SHERA; EGAN, 1951² apud CUNHA; CAVALCANTI, 2008, p. $52)$.

De acordo com Suaiden (2000, p. 57), “[...] a própria denominação 'biblioteca pública' pressupõe uma entidade prestando serviços ao público em geral, independentemente das condições sociais, educacionais e culturais.”. Ou seja, ela é capaz de reduzir as desigualdades sociais de acesso à informação, promovendo um ambiente democrático (MACHADO; SUAIDEN, 2013). Ademais, o objetivo da BP para a comunidade "[...] é melhorar a qualidade de vida da comunidade [...]" e "[...] assistir aos usuários através de um acervo compatível com as necessidades da população." (SUAIDEN, $1995^{3}$ apud ACHILLES, 2011, p. 4).

Sendo assim, a narrativa presente no main-stream possibilita o entendimento pelo qual qualquer cidadão é atraído a frequentar essa instituição. Contudo, esse estado da arte não é o que a pesquisa publicada no estudo Retratos da Leitura no Brasil (INSTITUTO PRÓ-LIVRO, 2012) aponta. O estudo levantado sobre o perfil do usuário de BP no Brasil revela que as pessoas que frequentam a biblioteca estão na faixa de cinco a dezessete anos. Ou seja, são usuários em idade escolar. Esse cenário surge como uma tendência na sociedade brasileira, considerando-se que, na década de 1980, Milanesi (1986, p. 113-114) afirma que “[...] o público dessas 
bibliotecas [...] é constituído fundamentalmente de estudantes de primeiro e segundo graus. [...] menos de $20 \%$ escapam da categoria estudantil”.

Isso corrobora a visão de que no Brasil ocorre um processo de escolarização da BP e que estas se apresentam como uma extensão da escola, um lugar onde os estudantes dos ensinos fundamental e médio são levados a realizarem suas pesquisas, pois muitas escolas não possuem bibliotecas. Ainda segundo Milanesi (2002, p. 47), as BP perderam a “[...] idéia da informação pública [e seguiram] o trajeto rumo aos currículos escolares e, por isso, entre outros motivos, deixaram de lado a população. [...] Com isso, o que seria público transformou-se em escolar.”. Logo, é possível pensar sobre a escolarização das BPs.

Medeiros (2010) afirma que as BPs sofrem uma crise de identidade, pois autoridades, cidadãos e até mesmo seus funcionários não sabem qual é a sua função. Suaiden (2000, p. 57) também fala sobre a dificuldade em saber o que esperar de uma BP, afirmando que

[...] os diversos segmentos da sociedade têm expectativas diferentes em relação ao papel da biblioteca pública. A indústria editorial acredita que o objetivo fundamental é a formação de um público leitor. Os educadores acreditam que a biblioteca deve ser o alicerce do processo ensinoaprendizagem. Os intelectuais acreditam que deve ser um espaço rico em literatura de ficção. O trabalhador comum não vê a biblioteca como um local para solucionar os problemas cotidianos.

Milanesi (1986, p. 95) adiciona a esse panorama:

Identificados como bibliotecas públicas estão armários com livros em salas fechadas; salas únicas para depósito e leitura (e trabalhos técnicos); várias salas, espaço para exposições, recinto para cinema e teatro, local para audiovisuais; salas com livros em escolas públicas; um armário com livros, fechado numa saleta que abriga outras atividades. Todas são "bibliotecas públicas".

Conforme uma das narrativas correntes, para que as BPs tenham uma identidade institucional e sejam reconhecidas como tal, suas ações e políticas são corroboradas por diretrizes internacionais, expressas no Manifesto sobre Bibliotecas Públicas, de 1994, elaborado pela Organização das Nações Unidas para a Educação, a Ciência e a Cultura (UNESCO). Como não possuem a força de uma Lei, a adoção das recomendações do referido Manifesto (e de outros anteriores) não se coloca 
como uma obrigação para as BPs, o que, juntamente com a inexistência de padrões, corrobora para a dificuldade no entendimento das características e particularidades das BPs em relação às demais tipologias de bibliotecas.

$\mathrm{Na}$ literatura, apesar de haver um predomínio dos debates e reflexões sobre a questão da BP qual é a função da BP na sociedade, com o passar dos anos, essa visão sofreu algumas mudanças. Analisando os Manifestos da UNESCO, temos:

a) no primeiro Manifesto escrito (UNESCO, 1949), a BP é vista como um produto da democracia moderna cuja função é incentivar a educação, entendida como um processo que ocorre ao longo da vida;

b) o segundo Manifesto (UNESCO, 1972) declara que a democracia é alcançada através da leitura de livros. Contudo, já são mencionados outros suportes que também contém informação e devem ser disponibilizados aos usuários.

No documento da UNESCO/INTERNATIONAL FEDERATION OF LIBRARY ASSOCIATIONS AND INSTITUTIONS (IFLA) (1994), a primeira missão elencada é "[...] criar e fortalecer hábitos de leitura nas crianças desde a mais tenra idade [...]", indo ao encontro da afirmação feita por Antônio Miranda (1978, p. 74): “A biblioteca pode oferecer toda sorte de serviços sem, porém, desvirtuar sua missão fundamental de promover o gosto e o hábito da leitura. Todas as atividades que ela organize devem servir para atrair e conquistar o leitor para tal missão.”. Além disto, a Fundação Biblioteca Nacional declara que:

[...] a biblioteca pública é o espaço privilegiado do desenvolvimento das práticas leitoras, e através do encontro do leitor com o livro forma-se o leitor crítico e contribui-se para o florescimento da cidadania. (2000, p. 17).

O cenário acima apresentado abre espaço para a reflexão em torno das relações entre livro, leitura, biblioteca e escola. No imaginário da sociedade brasileira, a biblioteca, e em particular a BP, está associada ao livro e à leitura e, nesse sentido, outras funções atribuídas às BPs no Brasil ${ }^{4}$ não são iluminadas. Pensar na biblioteca pública como um espaço para a construção da cidadania, através dos diferentes suportes de informação - não apenas do livro -, e como um lugar do encontro e do convívio entre diferentes sujeitos é uma perspectiva que vem 
se construindo ao longo dos últimos anos, no entanto, ainda não se apresenta como uma realidade para muitas bibliotecas públicas brasileiras.

Nessa perspectiva, é interessante anotar que o estado da arte no Brasil vem acompanhando o debate em âmbito internacional. Na segunda década do século XXI, a IFLA publica dois documentos que pautam a preocupação sobre os efeitos das TICs para as BPs e seus serviços, bem como a atenção ao descolamento entre a BP e o livro. A ênfase na busca da informação em outros meios se materializa no primeiro capítulo de um desses documentos, que aponta, por exemplo, no que concerne a função da BP na sociedade, “[...] a necessidade de uma instituição acessível a todos, que faculte acesso ao conhecimento na forma impressa, mas também através de outros formatos e meios como o multimédia ou a Internet [...]" (INTERNATIONAL FEDERATION OF LIBRARY ASSOCIATIONS AND INSTITUTIONS, 2012, p. 13).

As TICs, suas relações e aplicações para as BPs, bem como o seu poder em relação ao acesso e uso da informação são pontos enfatizados pelo documento intitulado Diretrizes da IFLA sobre os serviços da BP. Dois anos depois, tais questões - e respectivas relevâncias para as BPs - retornam ao centro do debate com o lançamento de outro documento pela IFLA. Com o sugestivo título de Riding the waves or caught in the tide?: navigating the evolving information environment, o documento pauta cinco tendências que mudarão o ambiente informacional (Quadro $1)$.

Quadro 1 - Tendências do ambiente informacional.

\begin{tabular}{|c|l|}
\hline $\begin{array}{c}\text { Tendência } \\
1\end{array}$ & Novas tecnologias irão tanto expandir como limitar quem tem acesso à informação \\
\hline $\begin{array}{c}\text { Tendência } \\
2\end{array}$ & A educação online democratizará e romperá as barreiras no aprendizado global \\
\hline $\begin{array}{c}\text { Tendência } \\
3\end{array}$ & As fronteiras de privacidade e de proteção de dados serão redefinidas \\
\hline $\begin{array}{c}\text { Tendência } \\
4\end{array}$ & Sociedades hiper-conectadas escutarão e legitimarão novas vozes e grupos \\
\hline $\begin{array}{c}\text { Tendência } \\
5\end{array}$ & A economia da informação global será transformada pelas novas tecnologias \\
\hline \multicolumn{2}{|c|}{ Fonte: INTERNATIONAL FEDERATION OF LIBRARY ASSOCIATIONS AND INSTITUTIONS } \\
([2013?], p. 4, tradução nossa).
\end{tabular}


Todas as tendências acima citadas possuem uma característica em comum: o impacto das novas tecnologias de informação no cotidiano das pessoas. De mais a mais, essas tendências dialogam com as funções das BPs, uma vez que ressaltam a necessidade do acesso à informação e apoiam a educação como aspecto importante na formação do cidadão, assim como promovem a inclusão social de diferentes grupos.

Apesar das reflexões no país sobre tais questões ainda estarem em processo de amadurecimento - tendo em vista que o acesso às TICs, de uma forma mais ampliada, é recente na sociedade brasileira ${ }^{5}$-, a questão já vem sendo pautada na literatura do campo informacional brasileiro há algumas décadas. De acordo com Milanesi, “[...] se ela [a BP] não ocupar os espaços que as necessidades sociais e os avanços tecnológicos criam, progressivamente será marginalizada como instituição do passado e, portanto, sem função.” (MILANESI, 1986, p. 12).

Assim, nas trilhas desse debate, propõe-se o estudo dos usos e apropriações das TICs pelas BPs brasileiras. No entanto, antes de uma aproximação com as BPs em análise e com a referida mídia social, faz-se necessário um diálogo com a noção de mediação sociotécnica.

\section{Mediação sociotécnica}

O conceito de mediação foi-se estabelecendo como ponto essencial nas pesquisas e reflexões sobre a comunicação/circulação de informação no campo informacional brasileiro. Muitos pesquisadores vêm estudando a noção de mediação. Dentre as definições mais citadas, encontra-se a de Almeida Júnior, que a define como

[...] toda ação de interferência - realizada pelo profissional da informação -, direta ou indireta; consciente ou inconsciente; singular ou plural; individual ou coletiva; que propicia a apropriação de informação que satisfaça, plena ou parcialmente, uma necessidade informacional. (ALMEIDA JÚNIOR, 2009, p. 92).

No entanto, essa conceituação presente na literatura da área vai de encontro ao senso comum dos profissionais da informação no Brasil. De acordo com Almeida Júnior (2009), há um entendimento da mediação como uma ponte, uma ligação entre 
dois pontos (no nosso caso entre os recursos informacionais e o usuário). Contudo, conforme enfatiza o autor, essa noção de ponte não é adequada, uma vez que ligação não é sinônimo de interferência - ação que ocorre na mediação. Ainda de acordo com o autor,

\begin{abstract}
A imagem da ponte parece inapropriada, em especial porque apresenta a ideia de algo estático, que leva alguma coisa de um ponto a outro ponto, sendo estes predeterminados e fixos, e sem interferir no trajeto, no modo de caminhar e no final do percurso. (ALMEIDA JÚNIOR, 2009, p. 92).
\end{abstract}

A leitura da mediação como algo que transcende a ligação entre dois pólos não é uma característica da produção brasileira sobre o tema. Davallon (2003) foi um dos autores que problematizou a ideia:

[...] a noção de mediação aparece cada vez que há necessidade de descrever uma acção implicando uma transformação da situação ou do dispositivo comunicacional, e não uma simples interacção entre elementos já constituídos - e ainda menos uma circulação de um elemento de um pólo para outro. (DAVALLON, 2003, p. 10).

Em outras palavras, a mediação para Davallon não é uma simples ligação, ou relação, entre dois extremos, pois há a produção de algo novo que irá satisfazer uma necessidade informacional através de transformação. A presença desse terceiro elemento (a produção de sentido) está em todos os tipos de mediação, seja ela feita pelo sujeito ou através de dispositivos tecnológicos. Portanto, ambos os autores concordam que mediar implica em transformar, interferir, no processo de apropriação da informação, não se configurando como algo estático.

É possível afirmar que essas ações de interferência passaram a ser mais notadas com a emergência das TICs, na medida em que as relações entre sujeitos e artefatos sociotécnicos ganharam destaque nos processos de construção de sociabilidade na sociedade contemporânea. Para Silva (2010), é evidente que o aparecimento das TICs introduziu uma dinâmica inteiramente nova na reprodução e na comunicabilidade dos conteúdos/informação, contribuindo para que esta coexista, sem alterações estruturais internas, em dois ou mais suportes diferentes.

Assim como Silva, Cornu $\left(2005^{6}\right.$ apud MARTELETO, 2010) também observa modificações ocorridas devido às TICs, pois o autor pondera que estas produziram uma rede bastante complexa, a World Wide Web (www), configurando- 
se como uma rede de informações. E é nesse ambiente da Internet, no ciberespaço, que se encontram as mídias sociais.

Com o intuito de refletir sobre o debate, em 2013, no Congresso Brasileiro de Biblioteconomia, Documento e Ciência da Informação (CBBD), Calil Júnior, Corrêa e Spudeit (2013) apresentaram a pesquisa $O$ uso das mídias sociais nas bibliotecas brasileiras: análise dos trabalhos apresentados no SNBU e CBBD. Esses três autores fizeram um levantamento sobre a literatura que fala de mídias sociais e constataram que alguns autores as entendem como um termo mais genérico, que abrange o conjunto de ferramentas da web 2.0 baseadas em interação social. É possível deparar-se com essa leitura no trecho de Recuero:

O que muitos chamam de "mídia social" hoje, compreende um fenômeno complexo, que abarca o conjunto de novas tecnologias de comunicação mais participativas, mais rápidas e mais populares e as apropriações sociais que foram e que são geradas em torno dessas ferramentas. É um momento de hiperconexão em rede, onde estamos não apenas conectados, mas onde transcrevemos nossos grupos sociais e, através do suporte, geramos novas formas de circulação, filtragem e difusão dessas informações. (RECUERO, 2011, p. 14).

Portanto, apesar de na literatura da área o termo "redes sociais" ser utilizado para conceituar o Facebook, neste artigo foi adotado o termo "mídias sociais", uma vez que as redes sociais não são exclusivas do ambiente virtual, como pode parecer ${ }^{7}$.

Qual seria, então, a conexão entre bibliotecas e o uso do Facebook? Sekyere (2009) observa que, tanto na literatura quanto em eventos da área, há a promoção do uso do Facebook pelas unidades de informação. No entanto, da mesma maneira que essa mídia social consegue alcançar inúmeras pessoas, é necessário refletir se o seu uso realmente será útil tanto para a instituição quanto para os usuários. O autor afirma que "[...] muitos dos serviços prestados pelas bibliotecas no Facebook possuem pouco uso, na verdade.” (SEKYERE, 2009, p. 26, tradução nossa). Nessa perspectiva, esse artigo pretende investigar os usos e as apropriações do Facebook por quatro Bibliotecas Públicas estaduais brasileiras: Biblioteca Pública do Estado do Acre, Biblioteca Pública do Paraná, Biblioteca Pública do Estado de Pernambuco e Biblioteca de São Paulo. 


\section{Metodologia}

Para analisar as apropriações do Facebook feitas pelas BPEs, primeiramente deve-se saber quais instituições usam tal mídia social. A estratégia adotada foi a de procurar pelo nome de cada Biblioteca no campo de busca dentro do próprio Facebook. Dentro desse campo, foi digitada a palavra "biblioteca". Faltando encontrar alguma biblioteca na primeira pesquisa, era acrescentado o nome do estado. Preferiu-se adotar essa estratégia ao se verificar, após visita aos diversos ambientes virtuais, que nem todas as mídias sociais são divulgadas nas páginas das Secretarias de Cultura ou Educação de cada estado, secretarias às quais as bibliotecas estão subordinadas no Brasil.

As seguintes BPEs fazem uso do Facebook (por ordem alfabética de estado):

a) Biblioteca Pública do Estado do Acre;

b) Biblioteca Pública do Estado da Bahia;

c) Biblioteca Pública Estadual Governador Menezes Pimentel (Ceará);

d) Biblioteca Pública do Espírito Santo;

e) Biblioteca Pública do Maranhão;

f) Biblioteca Pública Estadual Luiz de Bessa (Minas Gerais);

g) Biblioteca Pública do Paraná;

h) Biblioteca Pública do Estado de Pernambuco;

i) Biblioteca Estadual Des Cromwell de Carvalho (Piauí);

j) Biblioteca Pública Epifânio Dória (Sergipe);

k) Biblioteca Parque Estadual (Rio de Janeiro);

1) Biblioteca Pública do Estado do Rio Grande do Sul;

m) Biblioteca Pública do Estado II (Rio Grande do Sul);

n) Biblioteca de São Paulo.

Em uma análise preliminar, alguns fatos se destacam: primeiramente, não foi encontrada nenhuma BPE representando a região Centro-Oeste. Em segundo lugar, há dois perfis para a BP do Rio Grande do Sul, podendo causar confusão no momento em que o usuário for pesquisar a presença da Biblioteca na mídia social. Ademais, o perfil criado depois (Biblioteca Pública do Estado II) exige solicitação de amizade, o que nos leva ao terceiro ponto: percebe-se que não há consenso sobre qual tipo de 
conta criar: perfil pessoal, exigindo solicitação, ou fan page. Ao pedir solicitação, é possível que não haja resposta da Biblioteca, sendo esse um dos motivos pelo qual se recomenda que instituições utilizem a fan page.

Tendo em vista a extensão dos dados a serem analisados, para efeitos desse artigo, estipularam-se dois recortes: o primeiro, escolher quais BPEs teriam seu conteúdo analisado. Optou-se por escolher uma representante de cada região brasileira a fim de possibilitar uma visão mais próxima da realidade de cada região. De maneira aleatória, foram escolhidas a Biblioteca Pública do Estado do Acre, Biblioteca Pública do Paraná, Biblioteca Pública do Estado de Pernambuco e Biblioteca de São Paulo. Optou-se também por realizar um recorte temporal: foram coletadas as postagens realizadas entre os meses de janeiro e junho de 2013, observando o semestre letivo, totalizando seis meses.

Para que fosse possível analisar as fan pages, foram coletados alguns dados: a quantidade de curtidas durante o período selecionado, assim como a captura de todas as postagens presentes na linha do tempo das BPEs escolhidas através da captura das telas. Essa estratégia foi necessária visto que as páginas virtuais podem apresentar problemas técnicos e, às vezes, estar fora do ar.

Para efeitos da análise, optou-se por criar categorias. O processo de construção das categorias se deu a partir de uma leitura preliminar do conjunto de postagens realizadas pelos perfis das bibliotecas e do agrupamento de postagens semelhantes. Apresentam-se a seguir, no Quadro 2, as referidas categorias:

Quadro 2-Categorias das postagens.

\begin{tabular}{|c|l|}
\hline Categoria & \multicolumn{1}{c|}{ Temas } \\
\hline Eventos & $\begin{array}{l}\text { Compreendem a promoção das atividades organizadas pela Biblioteca e que } \\
\text { ocorrem dentro do seu espaço; simples divulgação de atividades que acontecem } \\
\text { fora da instituição, mas a Biblioteca interpreta como sendo importante divulgar; } \\
\text { visitas de autoridades e/ou de escolas. }\end{array}$ \\
\hline $\begin{array}{c}\text { Serviços da } \\
\text { biblioteca }\end{array}$ & $\begin{array}{l}\text { pesquisa sobre satisfação do atendimento; exibição de filmes; serviços oferecidos } \\
\text { para pessoas com necessidades especiais; divulgação do acervo; divulgação de } \\
\text { aquisição de novos livros; promoção de outras mídias sociais; mensagens sobre } \\
\text { serviços de empréstimo, renovação online e de alerta. }\end{array}$ \\
\hline
\end{tabular}




\begin{tabular}{|c|l|}
\hline Mensagens & $\begin{array}{l}\text { fazem parte dessa categoria postagens que mostram notícias que saem na mídia } \\
\text { sobre a Biblioteca; notícias da mídia que a Biblioteca julga ser relevante divulgar; } \\
\text { mensagens de usuários postadas na linha do tempo da Biblioteca; mensagens que a } \\
\text { própria Biblioteca publica (como, por exemplo, explicação de problemas no site, } \\
\text { ajuda para obter maior número de curtidas, publicação dos títulos mais pedidos, } \\
\text { informação de aniversário da Biblioteca e comemoração pelas visitas dos usuários } \\
\text { à instituição); mensagens sobre o universo da leitura (figuras, charges, situações } \\
\text { engraçadas ou de reflexão que acontecem com pessoas que leem bastante e } \\
\text { informações pequenas sobre autores) e, em alguns casos, divulgação do periódico } \\
\text { elaborado pela própria instituição. }\end{array}$ \\
\hline $\begin{array}{c}\text { Questões } \\
\text { administrativas }\end{array}$ & $\begin{array}{l}\text { postagens sobre horário de funcionamento; cancelamento de atividades e vagas de } \\
\text { estágio e/ou trabalho na própria instituição. }\end{array}$ \\
\hline Datas & $\begin{array}{l}\text { mensagens sobre festividades: dia do bibliotecário, dia do índio, dia da geografia, } \\
\text { aniversário de funcionário que compõe a equipe da Biblioteca (nessa categoria, não } \\
\text { há a intenção de fazer qualquer evento que chame os usuários a participarem de } \\
\text { atividades). }\end{array}$ \\
\hline comemorativas \\
\hline Fobituário & \begin{tabular}{l} 
informação sobre a morte de algum funcionário ou parente. \\
\hline publicação de fotos do ambiente da Biblioteca, apenas com o intuito de mostrar a \\
disposição do mobiliário da instituição.
\end{tabular} \\
\hline
\end{tabular}

Fonte: ALMENDRA (2014)

Com a definiç̧ão das categorias, passou-se à análise dos resultados.

\section{Apresentação dos dados e análise dos resultados}

Nessa seção, será apresentada a análise das fan pages de cada uma das Bibliotecas escolhidas, através de análises quanti e qualitativas. Essa investigação incidiu em categorias (e em seus componentes) com resultado consubstancial, ou seja, com amostragem maior que $15 \%$ das postagens.

\subsection{Biblioteca Pública do Estado do Acre}

O primeiro dado a ser analisado é o uso da ferramenta "curtir". A Biblioteca habilitou uma ferramenta que permite que seja vista a quantidade de curtidas recebidas a cada mês. De acordo com o período estabelecido e a coleta de dados, temos a seguinte tabela: 
Tabela 1 - Quantidade de curtidas recebidas pela BPE do Acre entre jan./jun.de 2013.

\begin{tabular}{|c|c|}
\hline Meses & Quantidade de curtidas \\
\hline Janeiro & 166 \\
\hline Fevereiro & 126 \\
\hline Março & 141 \\
\hline Abril & 127 \\
\hline Maio & 101 \\
\hline Junho & 164 \\
\hline
\end{tabular}

Fonte: Facebook (c2014)

Ao analisar a quantidade de interações a partir da ferramenta "curtir" e comparar tais números com os dados demográficos do estado do Acre - 336.038 mil habitantes, conforme o censo de 2010 (INSTITUTO BRASILEIRO..., 2010) -, há um indício de que a interação entre a fan page da biblioteca no Facebook e os sujeitos que residem no Acre é relativamente baixa. Ademais, é preciso considerar que não são apenas os naturais ou moradores do estado do Acre que possuem acesso à fan page.

Também foi possível verificar a quantidade de publicações ocorridas durante os meses de janeiro a junho de 2013: foram 366 postagens. Ao analisarmos essas postagens dentro das categorias anteriormente vistas, podemos perceber que, conforme o Gráfico 1 nos mostra, a maioria das publicações da Biblioteca é sobre serviços oferecidos pela instituição, num total de $74 \%$, ou 251 posts: 
Gráfico 1 - Proporção de postagens da BPE do Acre.

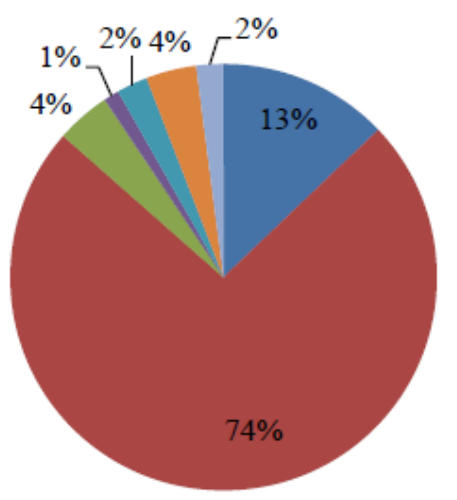

\author{
Eventos \\ - Serviços da biblioteca \\ Mensagens \\ @ Obituário \\ Datas comemorativas \\ Questões administrativas \\ Fotos
}

Fonte: Dados da pesquisa (2014)

Desses $74 \%$ de posts sobre serviços da BP, temos maior incidência de posts sobre exibição de filmes: foram 246 posts sobre exibição de filmes veiculados na fan page da Biblioteca.

Apesar de, com tais dados, não ser possível avaliar os motivos dessa alta incidência de postagens sobre exibições de filme, nota-se que há uma preocupação da biblioteca em chamar o seu usuário para frequentar o ambiente da instituição como local de lazer. Esse serviço vai ao encontro do que o documento Diretrizes da IFLA sobre os serviços da Biblioteca Pública, exposto na seção 2 deste trabalho, recomenda, pois a BP é vista como um local fornecedor de recreação e lazer (INTERNATIONAL FEDERATION..., 2012).

Como essas postagens não demandam interferência/participação dos fãs da página, o conteúdo postado é de caráter estático, uma vez que se entende que o objetivo da BP é de tornar pública a informação sobre os filmes exibidos na Biblioteca. Dessa forma, com esse tipo de postagem, a página assume função similar a de um quadro de avisos.

Como visto anteriormente, a categoria 'serviços da biblioteca' engloba mais do que exibição de filmes, pesquisa e serviços para pessoas com necessidades especiais. Contudo, os demais serviços citados acima não foram encontrados nessa fan page e, com o intuito de facilitar a compreensão do gráfico, foram suprimidos os serviços que tiveram incidência de nenhuma postagem. 


\subsection{Biblioteca Pública do Paraná}

Devido à ferramenta que mostra a quantidade de curtidas recebidas a cada mês, temos as ocorrências descritas na Tabela 2:

Tabela 2 - Quantidade de curtidas recebidas pela BP do Paraná entre jan./jun. de 2013.

\begin{tabular}{|c|c|}
\hline Meses & Quantidade de curtidas \\
\hline Janeiro & 234 \\
\hline Fevereiro & 244 \\
\hline Março & 292 \\
\hline Abril & 290 \\
\hline Maio & 317 \\
\hline Junho & 266 \\
\hline
\end{tabular}

Fonte: Facebook (c2014)

A tabela acima mostra que durante esse período, a fan page da BP do Paraná obteve o total de 1.643 curtidas. Uma vez mais, tomando por base os dados demográficos $^{8}$ do Instituto Brasileiro de Geografia e Estatística (IBGE), conclui-se que a interação entre a fan page e seus usuários, no que se refere ao uso da ferramenta curtir, é baixa.

Foram quantificadas, também, as publicações ocorridas durante os meses de janeiro a junho de 2013: 280 postagens. Na análise dessas postagens, levando-se em consideração as categorias vistas anteriormente, é possível perceber que a maioria das publicações da Biblioteca é sobre 'mensagens', num total de 49\%, ou 136 posts, conforme o Gráfico 2: 
Gráfico 2 - Proporção de postagens da BP do Paraná.

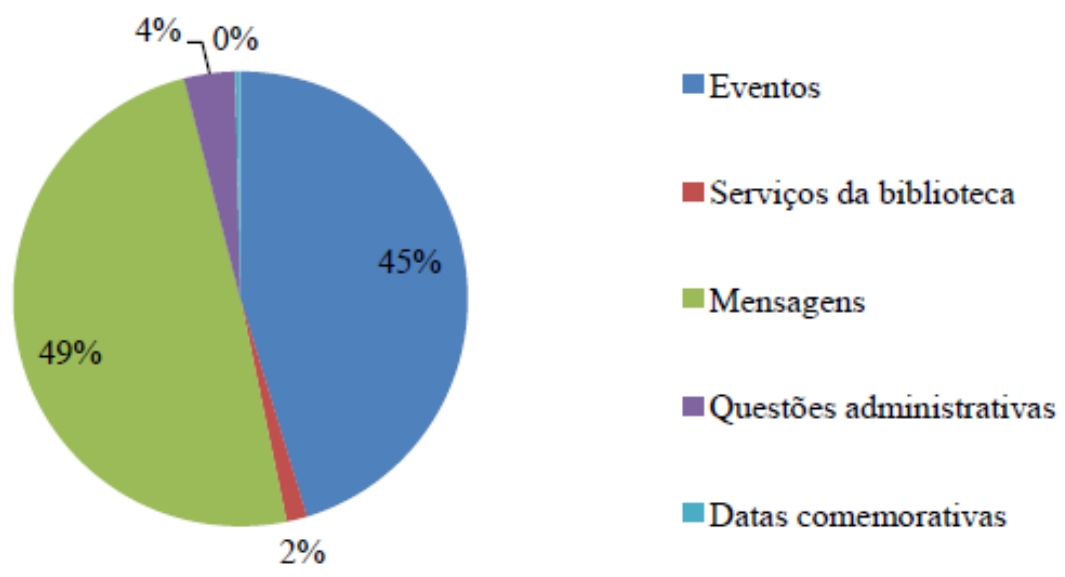

Fonte: Dados da pesquisa

$\mathrm{Na}$ coleta de dados, não foi encontrada nenhuma postagem sobre 'fotos' ou 'obituário', por isso essas categorias não aparecem no gráfico acima. Já a publicação de mensagens corresponde a 49\% das postagens (total de 136 posts), havendo maior ocorrência de posts (68 deles) sobre mensagens que divulgam matérias publicadas no periódico elaborado pela Biblioteca, o Jornal Cândido. Essa ocorrência talvez demonstre o cuidado em promover um produto da Biblioteca, divulgando notícias sobre autores, livros e eventos que fazem parte do cotidiano daquela instituição.

Outro ponto a ser destacado é que divulgações como essa abrem o espaço para o desenvolvimento de atividades voltadas para a construção da cultura informacional, na medida em que encaminham os usuários da fan page da Biblioteca no Facebook para outras fontes de informação.

Apesar de ter uma incidência menor comparado à categoria 'mensagens', 'eventos' aparece logo após, com 45\% das postagens feitas (125 publicações). Dentro dessa categoria, a maior ocorrência fica com os posts sobre divulgação de atividades que ocorrem dentro da BP do Paraná: são 122 posts sobre atividades realizadas dentro da Biblioteca, como os encontros de pessoas para jogarem RolePlaying Game (RPG). Considera-se que o destaque dado às atividades com jogos na biblioteca também faz parte do trabalho de estimular os usuários a frequentarem a Biblioteca não somente para a leitura, mas para atividades de lazer e socialização, integrando o objetivo principal de uma Biblioteca Pública segundo as Diretrizes da 
IFLA (2012), mostrando que as BPs servem como espaço de convívio entre diferentes públicos, conforme uma possível interpretação do documento.

\subsection{Biblioteca Pública do Estado de Pernambuco}

Diferente do que foi feito com as demais fan pages, o número de curtidas que a página recebeu a cada mês não pode ser analisado, uma vez que a ferramenta que permite aos usuários ver tais números não foi habilitada. Com isso, temos somente a informação recuperada no trabalho de Almendra (2013), que mostra a mesma página tendo um total de 708 curtidas desde que entrou no Facebook, em 2012, até o final do mês de junho de 2013 - número bastante inferior ao que se espera quando se leva em consideração a população da capital de Pernambuco, Recife, que tem 1.537.704 milhão de habitantes (INSTITUTO BRASILEIRO..., 2010). Dessa forma, tendo por base a interação a partir da ferramenta curtir, o padrão observado nas fan pages previamente analisadas se reproduz, ou seja, há pouca interação.

Durante os meses de janeiro a junho de 2013, foram capturadas 57 postagens. Comparando com as BP do Estado do Acre e a do Paraná, o índice de publicação na página é significativamente menor.

Levando-se em consideração todas as categorias mencionadas, a maioria das publicações dessa fan page é sobre mensagens, com um total de 20 posts, representando $35 \%$ das postagens feitas, conforme o Gráfico 3.

Gráfico 3 - Proporção de postagens da BPE de Pernambuco.

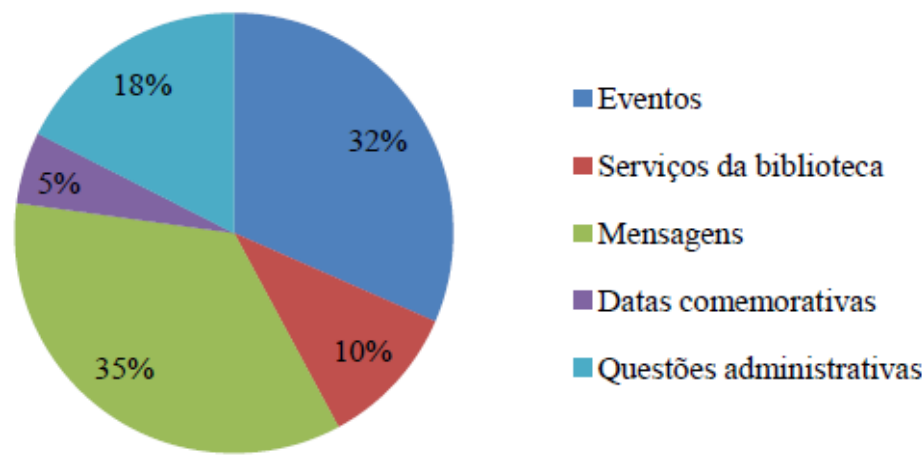

Fonte: Dados da pesquisa (2014) 
Dentro dessa categoria, vemos que a maior parte das publicações é sobre notícias da própria Biblioteca Pública: são 15 posts de notícias da Biblioteca que saíram em outras mídias, principalmente em entrevistas para a televisão, e 5 posts sobre notícias da mídia que a Biblioteca julga ser relevante divulgar. Uma possível interpretação para esse resultado é a preocupação da instituição em desenvolver um trabalho de marketing como estratégia para atingir usuários em potencial, uma vez que, assim como há um número pequeno de pessoas que curtiram a Biblioteca no Facebook, é provável que haja uma pequena parte da população usufruindo dessa instituição.

A categoria 'mensagens' vem seguida pela 'eventos'. Nesta, há maior incidência de posts sobre divulgação de atividades dentro da BP (11 postagens); em menor quantidade, há a de divulgação de atividades fora da BP (5 postagens) e, em último, visitas à biblioteca, com 2 publicações. Como exemplo de atividades realizadas dentro da $\mathrm{BP}$, há a divulgação de evento que promove a troca de livros usados por novos. A ênfase dada à divulgação de atividades associando a biblioteca, o livro e a leitura pode ser interessante na perspectiva da atração de um determinado público. No entanto, ao tratar apenas essa relação, reforça-se um determinado esteriótipo, da biblioteca como o espaço do livro e da leitura, em detrimento da noção da BP como o espaço do convívio entre diferentes públicos, através de atividades variadas, e da noção de que buscar a informação em outros meios além do livro é, da mesma forma, contribuir para a construção da cidadania.

A última categoria a ser analisada dentro das postagens da BP do Estado de Pernambuco é sobre 'questões administrativas', com um total de 10 posts somente sobre o horário de funcionamento. O conteúdo postado é de caráter estático, pois entendemos que o objetivo da BP é de tornar pública a informação de quando a BP voltará a abrir as portas, não demandando interferência/participação dos fãs da página, e assumindo, assim, função similar a de um quadro de avisos.

\subsection{Biblioteca de São Paulo}

Em relação ao número de curtidas, com a habilitação da ferramenta que nos mostra a quantidade de curtidas recebidas a cada mês, há a ocorrência descrita na Tabela 3: 
Tabela 3 - Quantidade de curtidas recebidas pela BSP entre jan./jun de 2013.

\begin{tabular}{|c|c|}
\hline Meses & Quantidade de curtidas \\
\hline Janeiro & 288 \\
\hline Fevereiro & 241 \\
\hline Março & 267 \\
\hline Abril & 287 \\
\hline Maio & 349 \\
\hline Junho & 300 \\
\hline
\end{tabular}

Fonte: Facebook (c2014)

A tabela acima mostra que durante esse período, a fan page da BSP alcançou o número de 1.732 curtidas. Almendra (2013) mostra que, até o final de junho de 2013, desde sua primeira postagem no Facebook, a página tinha o total de 5.439 curtidas. Considerando-se o total de habitantes da cidade de $\mathrm{SP}^{9}$, o número de interações a partir da ação de "curtir" ainda é baixo, mesmo sendo o de maior número entre as bibliotecas aqui analisadas.

Durante o período proposto a ser analisado, 618 postagens foram capturadas. Em comparação com as demais BPs aqui analisadas, o índice de publicação nessa página é significativamente maior.

Dentro das categorias anteriormente propostas, a maioria das publicações feitas é sobre 'mensagens', com o total de 320 posts, representando 52\% das postagens, seguida por 'eventos' $(27 \%$,) e 'serviços da biblioteca' (17\%), como percebemos no Gráfico 4: 
Gráfico 4 - Proporção de postagens da BSP.

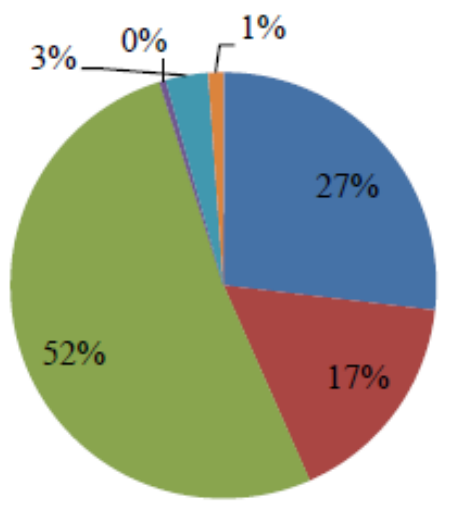

Eventos

- Serviços da biblioteca

Mensagens

Datas comemorativas

Questões administrativas

Fotos

Fonte: Dados da pesquisa

Na categoria 'mensagens', foram coletados 136 posts sobre o universo da leitura: figuras, charges, situações engraçadas ou de reflexão que acontecem com pessoas que leem bastante e informações pequenas sobre autores.

Figura 1 - Post sobre o processo de leitura.

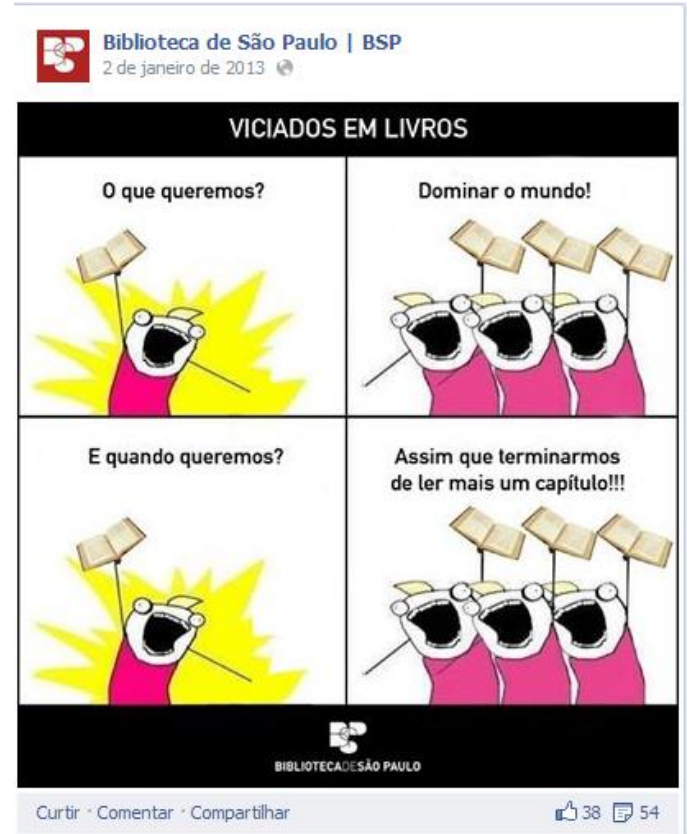

Fonte: Facebook (c2014) 
Ao tratar da leitura e da relação com o livro de uma forma mais descontraída, com uma linguagem menos formal, a BP abre possibilidades de diálogos com seus usuários (Figura 1).

A segunda categoria analisada é 'eventos', com $27 \%$ de todas as postagens recuperadas. Dentro dessa porcentagem, a maioria dos posts é sobre divulgação de atividades da BSP. São distintas as atividades que essa biblioteca promove: contação de histórias, oficina de xadrez, atividades lúdicas para bebês, bate-papo com autores e/ou discussão com outros profissionais, estimulando o convívio entre diferentes públicos. A leitura ainda é o pano de fundo da maioria dessas atividades (excetuando-se o xadrez), porém há a troca de informações através de outros meios - principalmente através da comunicação oral.

Por meio do Facebook é possível ter ciência das diferentes atividades promovidas, porém a utilização dessa fan page para a divulgação é feita de maneira estática, que não exige uma interferência/participação do usuário, assumindo o papel de um quadro de avisos.

Finalmente, a última categoria a ser investigada é a de 'serviços da biblioteca', na qual a maioria dos posts (total de 93) é de divulgação do acervo de livros. Aqui, a utilização do Facebook é de maneira a potencializar a divulgação dos livros, para que mais pessoas tenham conhecimento do que compõe o acervo. Entretanto, questiona-se o uso dessa mídia para difusão apenas de livros. Seria interessante se maximizassem o seu uso para divulgar outros tipos de suportes, como DVDs.

\section{Conclusão}

A IFLA recentemente lançou uma publicação contendo tendências que mudarão o ambiente informacional, e característica comum a todas elas se baseia no impacto das TICs no cotidiano das pessoas. Ao ressaltarem a necessidade do acesso à informação e a promoção da inclusão social de diferentes grupos, há um claro diálogo com as funções das BPs, uma vez que estas estimulam o bem estar social e o desenvolvimento democrático. Nessa perspectiva, a reflexão sobre como as BPEs 
estão se apropriando de tal tecnologia para mediar a informação nos remete ao debate sobre os efeitos das TICs no cotidiano dos cidadãos.

A pesquisa identificou a tentativa de aproximação entre $\mathrm{BP}$ e usuários através do uso de uma das mídias sociais de maior uso entre os brasileiros - o Facebook. Aliar as necessidades informacionais dos usuários às múltiplas possibilidades que o ciberespaço oferece é de extrema importância para as BPs, pois as mídias sociais podem intensificar o potencial do bibliotecário como mediador da informação, além de aumentar suas conexões com usuários, tanto reais como potenciais, uma vez que se mostra crescente o número de brasileiros que recorrem às mídias sociais como porta de entrada para a Internet.

Nesta perspectiva, é importante apontar a necessidade de estudos mais aprofundados não somente sobre as apropriações das mídias sociais pelos diferentes tipos de bibliotecas, mas também estudos sobre um tema bastante recente que merece atenção - a competência informacional em ambiente digital, pois a pesquisa sobre esse tema se mostra ainda incipiente no Brasil. Igualmente fundamental é estudarmos o lugar que a BP ocupa na sociedade contemporânea. O universo analisado neste trabalho representa uma parcela das BPEs brasileiras presentes no ciberespaço, ou seja, é apenas uma fração do conjunto dos equipamentos de informação disponíveis para uma parte da população que está cada vez mais conectada, segundo pesquisas veiculadas tanto na mídia quanto nos dados oficiais do governo. Conquanto, a investigação aqui realizada atualiza algumas questões e sugere que as bibliotecas, ao se apropriarem de um serviço no ciberespaço, não devem reiterar a mesma lógica praticada fora dos ambientes digitais. As diversas fan pages nas mídias sociais na Internet se constituem como uma ampliação do modelo físico. Logo, é exigida do bibliotecário uma atualização contínua para que se adapte a esse cenário de tecnologias em rede.

\section{Referências}

ACHILLES, Daniele. Bibliotecas públicas na sociedade brasileira. In: FÓRUM DE BIBLIOTECAS PÚBLICAS, 2., 2011, Maceió. Anais eletrônicos... Disponível em: $<$ http://www.bn.br/portal/arquivos/pdf/trabalhos_ii_forum_bibliotecas_publicas_201 1.pdf >. Acesso em: 22 fev. 2014. 
ALMEIDA JÚNIOR, Oswaldo Francisco de. Mediação da informação e múltiplas linguagens. Pesq. Bras. Ci. Inf., Brasília, v. 2, n. 1, p. 89-103, jan./dez. 2009.

ALMENDRA, Gabriela. As apropriações da mídia social Facebook pelas Bibliotecas Públicas Estaduais Brasileiras. 2014. 89 f. Trabalho de conclusão de curso (Graduação em Biblioteconomia) - Universidade Federal do Estado do Rio de Janeiro, Rio de Janeiro, 2014.

ALMENDRA, Gabriela . Mapeamento das apropriações das mídias sociais pelas Bibliotecas Públicas. JORNADA DE INICIAÇÂO CIENTÍFICA, 12., 2013, Rio de Janeiro. Resumos... Rio de Janeiro: UNIRIO, 2013. 1 DVD.

CALIL JÚNIOR, Alberto; CORRÊA, Elisa; SPUDEIT, Daniela. O uso das mídias sociais nas bibliotecas brasileiras: análise dos trabalhos apresentados no SNBU e CBBD. In: CONGRESSO BRASILEIRO DE BIBLIOTECONOMIA, DOCUMENTAÇÃO E CIÊNCIA DA INFORMAÇÃO, 25., 2013, Florianópolis. Anais eletrônicos... Florianópolis: Febab, 2013. p. 1-16. Disponível em: <http://portal.febab.org.br/anais/article/view/1634/1635>. Acesso em: 29 mar. 2014.

COMITÊ GESTOR DA INTERNET NO BRASIL. Pesquisa sobre o uso das tecnologias de informação e de comunicação no Brasil: TIC domicílios e TIC empresas 2013. São Paulo, 2014. Disponível em:

<http://cgi.br/media/docs/publicacoes/2/TIC_DOM_EMP_2013_livro_eletronico.pd f>. Acesso em: 10 mar. 2015.

\section{COMITÊ GESTOR DA INTERNET NO BRASIL. Pesquisa sobre o uso das} tecnologias de informação e de comunicação no Brasil: TIC domicílios e TIC empresas 2011. São Paulo, 2012. Disponível em: < http://op.ceptro.br/cgibin/cetic/tic-domicilios-e-empresas-2011.pdf>. Acesso em: 05 nov. 2013.

CUNHA, Murilo Bastos da; CAVALCANTI, Cordélia Robalinho de Oliveira.

Dicionário de Biblioteconomia e Arquivologia. Brasília: Brinquet de Lemos, 2008.

DAVALlON, Jean. A mediação: a comunicação em processo? Prisma.com, Porto, n. 4, p. 3-36, 2003. Disponível em:

<http://revistas.ua.pt/index.php/prismacom/article/view/645/pdf>. Acesso: 26 fev. 2014.

FACEBOOK. c2014. Disponível em: 〈https://www.facebook.com/facebook/info>. Acesso em: 7 abr. 2014.

FUNDAÇÃO BIBLIOTECA NACIONAL. Biblioteca Pública: princípios e diretrizes. 2. ed. Rio de Janeiro: Fundação Biblioteca Nacional/Sistema Nacional de Bibliotecas Públicas, 2010. 173 p. 
INSITUTO BRASILEIRO DE GEOGRAFIA E ESTATÍSTICA. Cidades@. [S.1.], 2010. Disponível em: 〈http://www.ibge.gov.br/cidadesat/index.php>. Acesso em: 2 jul. 2013.

\section{INSITUTO BRASILEIRO DE GEOGRAFIA E ESTATÍSTICA. Division into} regions. [S.1.], 2015. Disponível em:

<http://mapas.ibge.gov.br/en/escolares/publico-infantil/grandes-regioes>. Acesso em: 26 jan. 2015.

INSTITUTO BRASILEIRO DE OPINIÃO PÚBLICA E ESTATÍSTICA. Empresa de pesquisa. [S.I.], 2013. Disponível em: <http://www.ibope.com.br/pt$\mathrm{br} /$ relacionamento/imprensa/releases/Paginas/Numero-de-pessoas-com-acesso-ainternet-no-Brasil-chega-a-105-milhoes.aspx>. Acesso em: 26 jan. 2015.

INTERNATIONAL FEDERATION OF LIBRARY ASSOCIATIONS AND INSTITUTIONS. Diretrizes da IFLA sobre os serviços da Biblioteca Pública. 2. ed. Lisboa: IFLA, 2012.

INTERNATIONAL FEDERATION OF LIBRARY ASSOCIATIONS AND INSTITUTIONS. Riding the waves or caught in the tide?: navigating the evolving information environment. Holanda: IFLA, [2013?].

INSTITUTO PRÓ-LIVRO. Retratos da leitura no Brasil. 2012. Disponível em: <http://www.prolivro.org.br/ipl/publier4.0/texto.asp?id=2834>. Acesso em: $23 \mathrm{fev}$. 2014.

MACHADO, Elisa; CALIL JÚNIOR, Alberto; ACHILLES, Daniele. A biblioteca pública no espaço público: estratégias de mobilização cultural e atuação sóciopolítica do bibliotecário. Perspect. Ciênc. Info., v. 19, p. 115-127, 2014. Disponível em:〈http://portaldeperiodicos.eci.ufmg.br/index.php/pci/article/view/2263/1521〉. Acesso em: 22 jun. 2015.

MACHADO, Frederico Borges; SUAIDEN, Emir José. O papel da biblioteca pública e seus desafios frente aos avanços tecnológicos. In: CONGRESSO BRASILEIRO DE BIBLIOTECONOMIA, DOCUMENTAÇÃO E CIÊNCIA DA INFORMAÇÃO, 25., 2013, Florianópolis. Anais... São Paulo: FEBAB, 2013. Disponível em: <http://portal.febab.org.br/anais/article/view/1284>. Acesso em: 22 jan. 2014.

MANESS, Jack M. Teoria da biblioteca 2.0: Web 2.0 e suas implicações para as bibliotecas. Informação \& Sociedade, João Pessoa, v. 17, n. 1, p. 43-51, jan./abr. 2007.

MARTELETO, Regina Maria. Redes sociais, mediação e apropriação de informações: situando campos, objetos e conceitos na pesquisa em Ciência da Informação. Tendências da Pesquisa Brasileira em Ciência da Informação, Brasília, v. 3, n. 1, p. 27-46, jan./dez. 2010. 
MEDEIROS, Ana Ligia Silva. Biblioteca e cidadania. Sinais Sociais, Rio de Janeiro, v. 4, n. 13, p. 10-45, maio/ago. 2010.

MILANESI, Luiz Augusto. Biblioteca. Cotia: Ateliê Editorial, 2002.

MILANESI, Luiz Augusto. Ordenar para desordenar: centros de cultura e bibliotecas públicas. São Paulo: Brasiliense, 1986.

MIRANDA, Antônio. A missão da biblioteca pública no Brasil. Revista de Biblioteconomia de Brasília, Brasília, v. 6, n. 1, p. 69-75, jan./jun. 1978.

RECUERO, Raquel. A nova revolução: as redes são as mensagens. In:

BAMBRILlA, A. (Org.) Para entender as mídias sociais. [S.1]: [s.n], 2011.

Disponível em: <http://issuu.com/anabrambilla/docs/paraentenderasmidiassociais>. Acesso em: 29 mar. 2014.

SEKYERE, Kwabena. Too much Hullabaloo about Facebook in Libraries! Is it really helping libraries?. Nebraska Library Association Quarterly, v. 40, n. 2, p. 2527, 2009. Disponível em: <http://nebraskalibraries.org/>. Acesso em: 29 mar. 2014.

SILVA, Armando Malheiro da. Mediações e mediadores em Ciência da Informação. Prisma.com. Porto, n. 9, p. 1-37, 2010. Disponível em: $<$ http://revistas.ua.pt/index.php/prismacom/article/view/700>. Acesso em: 8 abr. 2014.

SILVEIRA, Fabrício José Nascimento da; REIS, Alcenir Soares dos. Biblioteca pública como lugar de práticas culturais: uma discussão sócio-histórica. Informação \& Sociedade, João Pessoa, v. 21, n. 1, p. 37-54, jan./abr., 2011.

SORJ, Bernardo. Information society and digital device. Milão: Polimétrica, 2008.

SUAIDEN, Emir José. A biblioteca pública no contexto da sociedade da informação. Ci. Inf., Brasília, v. 29, n. 2, p. 52-60, maio/ago. 2000.

ORGANIZAÇÃO DAS NAÇÕES UNIDAS PARA A EDUCAÇÃO, A CIÊNCIA E A CULTURA. The public library: a living force for popular education. Paris: UNESCO; LBA, 1949.

ORGANIZAÇÃO DAS NAÇÕES UNIDAS PARA A EDUCAÇÃO, A CIÊNCIA E A CULTURA. Manifeste de l'Unesco sur la bibliothèque publique. Paris: UNESCO, 1972.

ORGANIZAÇÃO DAS NAÇÕES UNIDAS PARA A EDUCAÇÃO, A CIÊNCIA E A CULTURA. INTERNATIONAL FEDERATION OF LIBRARY ASSOCIATIONS AND INSTITUTIONS. Manifesto da UNESCO sobre bibliotecas públicas. 1994. Disponível em: <http://snbp.bn.br/manifesto-da-unesco-sobre-bibliotecaspublicas/>. Acesso em: 18 jan. 2014. 


\title{
The appropriation of Facebook by Brazilian public libraries
}

\begin{abstract}
This paper aims to present a study on the appropriation of the social media Facebook by four Brazilian State Public Libraries: the Public Library of the State of Acre, the Public Library of the State of Paraná, the Public Library of the State of Pernambuco and the Public Library of the State of São Paulo. The study, based on literature review, addresses the concepts of Public Libraries, sociotechnical mediation and social media. It questions the role of the Public Library in the contemporary society and claims that libraries should, through mediation, recognize the importance of their space as a room for dialog, exploiting it as a means of communication and interaction. The study also analyses the messages posted in the aforementioned Libraries in the period that goes from January to June 2013. It concludes that the social media studied is not utilized at its full potential.
\end{abstract}

Keywords: State public libraries. Mediation. Information literacy. Social media. Facebook.

Recebido em: 13/04/2015

Aceito em: 29/06/2015

${ }^{1}$ O Brasil possui cinco divisões regionais (INSTITUTO BRASILEIRO..., 2015).

${ }^{2}$ SHERA, Jesse H.; EGAN, Margaret E. (Ed.). Bibliographic organization. Chicago: University of Chicago, 1951.

${ }^{3}$ SUAIDEN, Emir José. Biblioteca Pública e informação à comunidade. São Paulo: Global, 1995

${ }^{4}$ A literatura do campo informacional no Brasil está repleta de análise sobre a função da Biblioteca Pública na sociedade brasileira. Para maiores detalhes, ver Silveira e Reis (2011).

${ }^{5}$ Para uma reflexão sobre a inclusão digital no Brasil, ver Sorj (2008). Já em relação às transformações ocorridas nas políticas públicas para bibliotecas no Brasil, ver a análise de Machado, Calil Júnior e Achilles (2014).

${ }^{6}$ CORNU, B. Réseau. In: COMMISSION FRANÇAISE POUR 1'UNESCO. La société de l'information: glossaire critique. Paris: La Documentation Française, 2005. p. 121-123

7 "Nos dias atuais, é comum associar a expressão - redes sociais - aos encontros e aos espaços virtuais de interação, relacionamento e colaborações na Internet. $\mathrm{O}$ uso do termo se faz de maneira tão alusiva e esquemática ao ponto de se deixar de lado, muitas vezes, seu trânsito histórico e epistemológico, tanto quanto seu alcance 
conceitual e metodológico para estudar fenômenos sociais de interações e trocas nas sociedades complexas". (MARTELETO, 2010, p. 31).

${ }^{8}$ População de Curitiba (capital do Paraná): 1.751 .907 milhão de habitantes (INSTITUTO BRASILEIRO..., 2010).

${ }^{9}$ População de São Paulo (capital): 11.253.503 milhões de habitantes (INSTITUTO BRASILEIRO..., 2010). 